parasitology, epidemiology ; insecticides, vermifuges, and antimalarial drugs; rickettsia; and animal parasites, and are clearly set out and described. Further information about the list, which contains English translations of the French text, may be obtained from W. de Vogel, Catharijnesingel 59, ingang Sterrenbos, Utrecht, Holland.

\section{A New Core-sampler}

AN almost unexplored record of the Earth's history is preserved in the sediment under the great oceans. Profiles of the uppermost layers have been obtained by many different types of corer, and to this list Prof. B. Kullenberg has now added a modified version of his elegant piston corer which should reach deeper than ever before (Meddelanden frain Oceanografiska Institutet, Göteborg, 26, 1955. Göteborgs Kungl. Vetenskaps-och Vitterhets-Samhälles Handlingar. Sjätte Foljden. Ser. B, 6, No. 15). The new corer carries the same weight as the old model, 1,500 kgm., but has greater penetrating power, because with a length of only $2 \cdot 3$ metres there is a relatively small area of wall in frictional contact with the sediment. With such a design the driving weight must enter the sediment and so the weight encases the tube and is shaped to cause ninimum drag. The corer sinks down through the sediment to a depth determined by the length of cable wrapped around its upper end. When all this cable has been unwound, the piston, which up to now has been locked at the lower end of the corer, is released and a core is taken. Although this ingenious corer has reached down to $29 \mathrm{~m}$. and is expected to reach $50 \mathrm{~m}$. in soft sediment, it is only suited to giving 'spot' samples, and so there still remains the ultimate problem of how to reach and take a continuous profile of sediment which can be a full kilometre thick.

\section{Physics of Nuclear Fission}

A symposium on the physics of fission was held at Chalk River, Ontario, Canada, in May 1956, and a detailed account of the proceedings has been published as a report by Atomic Energy of Canada, Ltd. (AECL No. 329, pp. $414 ; 5$ dollars). The twenty papers presented are in the nature of authoritative reviews of the present state of knowledge, rather than reports of original research, since the symposium had a mainly educational purpose. An introductory section outlines the experimental results of low. energy and high-energy fission ('low-energy' and 'highenergy' here refer to the excitation energy of a nucleus before fission, the dividing line being at roughly $20 \mathrm{MeV}$.$) , and the discrepancies between$ observation and the predictions which can be made on the basis of the liquid drop nuclear model. Subsequent sections deal with the probability of fission (including spontaneous fission and photofission), the detailed experimental results, and the theoretical aspects. A summary of the spirited discussion which took place is given at the end of each section, and many diagrams and references are also given. The report is an excellent and comprehensive survey of the experimental results of fission physics and the extent to which they can be interpreted on current nuclear theories, and gives well-informed views on the directions in which future work may develop. It is stated that a classified supplement has been prepared; but it is unlikely that physicists interested in the fundamentals of nuclear fission will be frustrated by the requirements of secrecy, which nowadays cover a rather small area.

\section{Spring Strips}

SPRING strips made of tempered steel or other elastic materials are used extensively in the construction of many types of measuring instruments. Flexible couplings, pivots, simple means of obtaining parallel motion, and the magnification of small movements are among their more common applications, and their particular advantages are freedom from friction, play and wear, and the absence of lubrication. Instrument design may often be considerably simplified and the cost of manufacture reduced by using spring strips, and in order to assist designers and provide them with a knowledge of the general principles of function of some of the more useful arrangements of spring strips the National Physical Laboratory, Teddington, has recently published Notes on Applied Science, No. 15, "Applications of Spring Strips to Instrument Design" (H.M. Stationery Office, $1956 ; 2 s$. net). In its various sections, singlestrip pivots, cross-spring pivots, parallel motion, conversion of linear into angular motion, buckling strips and twisted spring strips are dealt with, and both theoretical and numerical data are quoted together with suitable applications of the mechanisms. In the final section a brief discussion is given of methods of attaching spring strips to related parts of instrument mechanisms, the most common method being the use of clamping plates. The text of the booklet is adequately illustrated by clearly-drawn line drawings and graphs.

\section{Solar Deflexion of Light}

THE deflexion of starlight by the gravitational field of the Sun forms one of the three well-known tests of the theory of relativity. Einstein's theory predicts that a ray of light passing close to the Sun will be deflected through an angle twice that predicted by Newtonian mechanics. While the relativistic effect has been discussed in print on many occasions, it is rare to find a text-book which treats the problem by means of Newtonian mechanics. Teachers and students will therefore be glad to have such a treatment available, and Dr. M. Davidson (J. Brit. Astro. Assoc., 66, 268; July 1956) has provided one, deriving the result from first principles without even the use of the usual formulæ of dynamical astronomy ; the use of the latter formula would provide a still shorter derivation.

\section{Publication of Lectures in Biochemistry}

WHEN possible, the Biochemistry Department, University College, London, intends to publish the public lectures given in the Department by invited lecturers. The first instalment covers the year 195455 and contains lectures on the catalytic activity of vitamin $B_{6}$ by E. E. Snell (Texas), on the respiratory mechanisms in bacteria by S. R. Elsden (Sheffield), and on metal complexes and metallo-enzymes by R. J. P. Williams (Oxford). A full report of a colloquium on biochemical aspects of chelation is also included. These public lectures were anything but 'popular', but it is good to have them made available to a wider circle of specialists. The distributing agents are Messrs. H. K. Lewis, London.

\section{Handbook of Magnesium-Organic Compounds}

"A HANDBooK of Magnesium-Organic Compounds", by S. T. Yoffe and A. N. Nesmeyanov (in three volumes, with a foreword by Prof. W. Wardlaw, translations and notes by Dr. A. L. Mackay. Pergamon Press, London and New York, 1956; £24, 